Article

\title{
Formation of Bimetallic Fe/Au Submicron Particles with Ultrasonic Spray Pyrolysis
}

\author{
Peter Majerič $^{1,2, *}$, Darja Jenko $^{3}$, Bernd Friedrich ${ }^{4}$ (D) and Rebeka Rudolf ${ }^{1,2}$ (D) \\ 1 Faculty of Mechanical Engineering, University of Maribor, Smetanova ulica 17, Maribor 2000, Slovenia; \\ rebeka.rudolf@um.si \\ 2 Zlatarna Celje d.o.o., Kersnikova 19, Celje 3000, Slovenia \\ 3 Institute of Metals and Technology, Lepi pot 11, Ljubljana 1000, Slovenia; darja.jenko@imt.si \\ 4 IME Process Metallurgy and Metal Recycling, RWTH Aachen University, Intzestrasse 3, 52065 Aachen, \\ Germany; bfriedrich@ime-aachen.de \\ * Correspondence: peter.majeric@um.si; Tel.: +386-31-214-764
}

Received: 2 March 2018; Accepted: 16 April 2018; Published: 18 April 2018

check for updates

\begin{abstract}
This article studies the synthesis of bimetallic Fe/Au submicron particles with Ultrasonic Spray Pyrolysis (USP). The combination of Fe oxide particles' ferromagnetism with Au nanoparticles' (AuNPs) surface plasmon resonance has gained high interest in biomedical and various other applications. Initial investigations for producing $\mathrm{Fe} / \mathrm{Au}$ particles with USP were carried out in order to study the particle formation mechanisms. Firstly, three precursor salt solutions (Fe acetate, Fe nitrate and Fe chloride) were used to produce Fe oxide particles and to study their effect on particle morphology through characterization by Scanning and Transmission Electron Microscopy (SEM and TEM) with Energy Dispersive X-ray spectroscopy (EDX). These precursor salts produce three types of submicron particles, a mesh of primary nanoparticles, spherical particles and irregular particles, respectively. Next, different solution combinations of precursor salts of Fe and Au were used with the USP. The obtained particles were characterized, and similarities were then examined in the particle formation of pure Fe oxide and Fe/Au particles. The effects of using different salts were analyzed for the formation of favorable morphologies of Fe/Au particles. The combinations of Fe chloride/Au chloride and Fe chloride/ $\mathrm{Au}$ nitrate in the precursor solution indicate potential in synthesizing bimetallic Fe/ Au submicron particles with the USP process.
\end{abstract}

Keywords: ultrasonic spray pyrolysis; precursor salts; formation mechanism; nanoparticle structure; Fe oxides; $\mathrm{Au}$

\section{Introduction}

Several research works have been done for bimetallic Fe/ Au nanostructures [1,2], with a strong interest in biomedical applications [3,4], and also with an additional intermediate layer between the magnetic Fe core and the plasmonic Au layer $[5,6]$. The goal is to enhance or develop a functional material for targeted applications joining two elements in some type of construction, such as core-shell, alloy or otherwise $[7,8]$. Joining the properties of these elements produces different effects, such as enhanced catalysis or tunable plasmonic properties, making the hybrid structures useful for a number of applications (catalysis [7], sensors [7], magnetic resonance imaging [3,4,9], photothermal treatment of cancer [3-5] and drug delivery systems [3,4,9]). Our previous research studied the production of gold nanoparticles (AuNPs) with Ultrasonic Spray Pyrolysis (USP) extensively [10]. AuNPs have good potential for various applications due to their properties, such as surface plasmon resonance and high biocompatibility. This work endeavors to add an additional property to these nanoparticles produced by USP, ferromagnetism. The aim is to obtain gold ( $\mathrm{Au}$ )-coated iron (Fe) nanoparticles, 
having magnetic core properties, with the surface plasmon resonance and conjugation capabilities of the gold shell.

USP is a relatively well-known nanoparticle synthesis process, producing nanoparticles from a starting solution with the desired dissolved material (precursor) [11]. The prepared precursor solution is subjected to ultrasound, forming aerosol droplets of a few micrometers in size. The droplets are then transported into a tube furnace with a carrier gas. The temperature inside the tube furnace is high enough so that the formation of nanoparticles can take place (depending on the precursor). A reaction gas is also present in the tube furnace. As the droplets reach a higher temperature inside the furnace, they undergo solvent evaporation (usually water evaporation), particle drying, particle reactions with the reaction gas and, finally, particle densification.

In our research, we have made AuNPs successfully with the redesign of the conventional USP, using hydrogen tetrachloroaurate $\mathrm{HAuCl}_{4}$ (gold chloride) dissolved in deionized water as the precursor [10]. The redesign has produced more uniformly-shaped AuNPs than before, depending on the parameters (gold concentration in the precursor, gas flows and temperatures). This also enabled us to identify a bimodal size distribution, which was the result of different formation mechanisms being carried out in the reaction furnace. One is the Droplet-To-Particle (DTP) mechanism [12], where a single particle is formed from a single droplet (larger AuNPs). The other is the Gas-To-Particle (GTP) mechanism [12], where the evaporation of a single droplet also evaporates the material inside, and the vapors then form several smaller particles from a single droplet. Another possible mechanism is DTP from exploded droplets. As the somewhat larger droplets enter a higher temperature, they may burst into several smaller droplets, from which smaller nanoparticles are then formed via the DTP mechanism [10]. Using different USP process parameters favors different formation mechanisms inside the tube furnace.

The most common magnetic nanoparticles are iron oxides, namely magnetite $\left(\mathrm{Fe}_{3} \mathrm{O}_{4}\right)$ and maghemite $\left(\gamma-\mathrm{Fe}_{2} \mathrm{O}_{3}\right)$ [13]. With sizes below $30 \mathrm{~nm}$, these nanoparticles are superparamagnetic, while otherwise they are ferromagnetic [6]. With spray pyrolysis, maghemite nanoparticles have been produced with different iron precursor salts in solutions with alcohol [14,15]. Magnetite oxidizes into maghemite easily $[13,15]$, making it more difficult to produce in the USP system due to it being exposed environmentally to oxidizing factors such as in the precursor solution or the collection medium (when using water or alcohols).

In this paper, an initial investigation for producing $\mathrm{Fe} / \mathrm{Au}$ bimetallic particles was carried out in the USP device in order to study its particle formation mechanisms and to advance the understanding and development of the USP process. Adding a ferromagnetic property to the plasmonic nanoparticles has interesting potential uses in various applications, from catalysis to energy conversion [6]. However, the main focus of research for this type of materials is on a wide range of biomedical applications, such as imaging, tissue engineering, cellular sorting, therapy and targeted drug delivery [2-6,16].

This investigation was conducted in order to study the possibilities and capabilities of USP for bimetallic Fe/Au nanoparticle production and to examine the formation mechanisms taking place inside the USP furnace when using a precursor with two dissolved materials, Fe and Au.

\section{Materials and Methods}

\subsection{Experiments}

Different precursor combinations of Fe- and Au-containing salts were used in preparing the precursor solutions for investigating different formation mechanisms. Thermogravimetric analyses (TGA) of the used Fe salts were performed first, in order to ensure that the formation of pure Fe was carried out inside the USP furnace. TGA for the Au-containing salts were performed in our previous investigations $[10,17]$. The precursor solutions used with dissolved $\mathrm{Fe}$ and $\mathrm{Au}$ salts are shown in Table 1. The salts used were as follows:

- Iron (II) acetate, trace metals basis $\geq 95 \%$, Molekula (München, Germany) 
- Iron (III) chloride hexahydrate, trace metals basis $\geq 98 \%$, Molekula (München, Germany)

- Iron (III) nitrate nonahydrate, trace metals basis $\geq 98 \%$, Molekula (München, Germany)

- Gold (III) chloride tetrahydrate, trace metals basis $\geq 99.9 \%$, Acros Organics (Pittsburgh, PA, USA)

- Gold (III) acetate, trace metals basis $\geq 99.9 \%$, Alfa Aesar (Haverhill, Massachusetts, USA)

- Gold (III) nitrate, trace metals basis $\geq 99.9 \%$, American Elements (Los Angeles, California, USA)

The prepared solutions, with a volume of 1 liter each, were put into the solution chamber of an ultrasonic generator Gapusol 9001, RBI (Meylan, France), with three ultrasonic transducers, each with an ultrasound frequency of $2.5 \mathrm{MHz}$. The carrier and reduction gas were passed through the chamber into a $1.8 \mathrm{~m}$-long vertical quartz tube with a diameter of $42 \mathrm{~mm}$. The USP equipment used in the experiments is described in previous publications [18]. The quartz tube is positioned inside three heating zones of lengths of $0.4 \mathrm{~m}, 1 \mathrm{~m}$ and $0.4 \mathrm{~m}$ (pre-heating, reaction and cooling). The temperatures of the reaction furnace sections were 600,600 and $300{ }^{\circ} \mathrm{C}$. Nitrogen was used as the aerosol carrier gas, and hydrogen was used for the reactions. The gas flow was $4 \mathrm{~L} / \mathrm{min}$ for nitrogen and $2 \mathrm{~L} / \mathrm{min}$ for hydrogen. The tube system was under a small vacuum of about $980-990$ mbar. The particles were collected in an electrostatic filter, which was also heated to $150{ }^{\circ} \mathrm{C}$ in order to prevent re-condensation of the droplet evaporated water vapor in the filter. Additional water bottles were connected to the filter for collecting any particles that may have escaped the electrostatic field inside the filter. The list of experiments performed is seen in Table 1.

Table 1. List of experiments performed, with the Ultrasonic Spray Pyrolysis (USP) parameters.

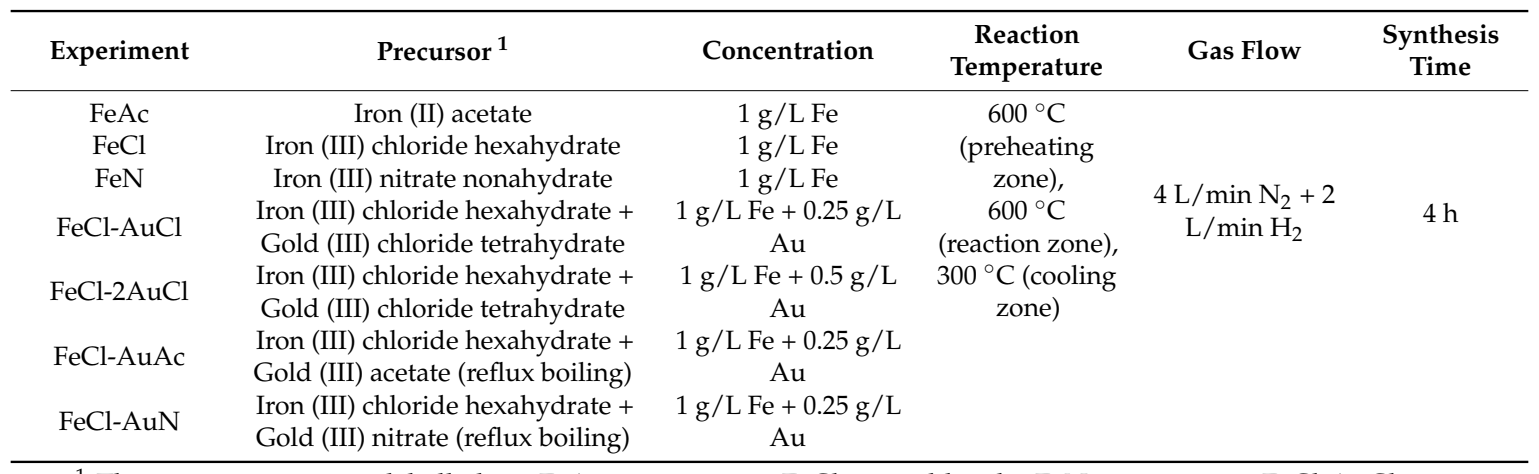

${ }^{1}$ The experiments were labelled as: $\mathrm{FeAc}$, iron acetate; $\mathrm{FeCl}$, iron chloride; $\mathrm{FeN}$, iron nitrate; $\mathrm{FeCl}-\mathrm{AuCl}$, iron chloride with gold chloride; $\mathrm{FeCl}-2 \mathrm{AuCl}$, iron chloride with a double concentration of gold chloride; $\mathrm{FeCl}-\mathrm{AuAc}$, iron chloride with gold acetate; $\mathrm{FeCl}-\mathrm{AuN}$, iron chloride with gold nitrate.

\subsection{Characterization}

The produced $\mathrm{Fe}$ oxide and $\mathrm{Fe} / \mathrm{Au}$ particles were characterized with Scanning Electron Microscopy (SEM) using a Sirion 400NC (FEI, Hillsboro, OR, USA) and Transmission Electron Microscopy (TEM) using a JEOL JEM-2200FS (JEOL, Akishima, Tokyo, Japan) and a probe-corrected Titan Themis 60-300 (FEI, Hillsboro, OR, USA), both with integrated Selected Area Electron Diffraction (SAED) pattern analysis, operating at $200 \mathrm{kV}$ and $300 \mathrm{kV}$, respectively. SEM and TEMs were equipped with Energy-Dispersive X-ray spectroscopy (EDX), which was used for the determination of the chemical analysis. A small sample of the powder collected from the USP filter was deposited onto carbon film holders for SEM investigations. Samples for TEM analyses were mixed with ethanol and drop cast on a copper TEM grid covered with amorphous carbon support film, dried and then used for investigations. The sizes of the particles were measured from the SEM and TEM micrographs with the ImageJ software (NIH, Bethesda, MD, USA) [19]. The particles were measured from 8-12 images of varying magnifications per sample, and the number of measured particles is given in Tables 2 and 3 . Their shapes and elemental composition, needed for the formation mechanism investigations, were examined from the SEM and TEM micrographs and EDX spectroscopy data. 
DLS of the resulting particles was also performed for zeta potential measurements using a Malvern Zetasizer Nano ZS (Malvern Instruments Ltd., Malvern, UK). The samples for zeta potential measurements were dispersed in de-ionized water until they were slightly turbid (as recommended in the Malvern Zetasizer Nano ZS manual). If the Zetasizer reported an inappropriate sample concentration, a higher concentration was given for the sample. The measurement parameters used were: refractive index 0.20 , absorptivity 3.32 , temperature $25^{\circ} \mathrm{C}$, water with dispersant properties, equilibration time 25 seconds, $173^{\circ}$ backscatter measurement angle, samples measured in a dip cell with electrodes with a volume of $1 \mathrm{~mL}$. Three measurements were made per sample, and the mean results are given in Table 4.

\section{Results and Discussion}

In the first step, iron-containing precursors were used with USP, in order to understand the morphologies and synthesis mechanisms of Fe oxide particles that are formed inside the USP better. Three precursors were used for this purpose: iron (II) acetate $\left(\mathrm{Fe}\left(\mathrm{C}_{2} \mathrm{H}_{3} \mathrm{O}_{2}\right)_{2}\right)$, iron (III) chloride hexahydrate $\left(\mathrm{FeCl}_{3} \times 6 \mathrm{H}_{2} \mathrm{O}\right)$ and iron (III) nitrate nonahydrate $\left(\mathrm{Fe}\left(\mathrm{NO}_{3}\right)_{3} \times 9 \mathrm{H}_{2} \mathrm{O}\right)$. The same USP parameters (reaction temperature, ultrasound frequency, gas flow) were chosen for all three precursor types for a direct comparison of the resulting Fe particle morphology. TGA was done on the precursors in order to select a reaction temperature inside the USP, ensuring Fe oxide particle synthesis. The following temperatures are needed for total thermal decomposition of the precursor salts: iron acetate (labelled FeAc) $275.45^{\circ} \mathrm{C}$, iron chloride (labelled $\mathrm{FeCl}$ ) $463.36{ }^{\circ} \mathrm{C}$ and iron nitrate (labelled FeN) $175.68^{\circ} \mathrm{C}$. A temperature of $600{ }^{\circ} \mathrm{C}$ ensures that the synthesis of all three precursors would result successfully in the formation of Fe oxide particles, with ample reaction time (about 19.4 s inside the first two heating zones) for complete decomposition of the precursors inside the USP reaction zone. From the three precursors, three distinctive Fe oxide particle shapes have been formed inside the USP (Figure 1). Table 2 shows the measured sizes of the obtained particles. In Figure 1, the size distributions are shown only up to $600 \mathrm{~nm}$, as the number of particles above this size is below $5 \%$ (percentage of particles above $600 \mathrm{~nm}$ : FeAc 2.95\%, $\mathrm{FeCl} 3.37 \%$ and $\mathrm{FeN} 4.14 \%$ ). The size of particles synthesized with USP is dependent mainly on the aerosol droplet size, precursor solution density, viscosity and surface tension and precursor salt concentration $[20,21]$. Since all three experiments had the same ultrasonic generator with the precursor solution physical properties similar to water, with the same low salt concentration, the measured particle sizes were similar between the three experiments. The mean size values between the experiments did not differ by much (about $261 \mathrm{~nm}$ for FeAc, $283 \mathrm{~nm}$ for $\mathrm{FeCl}$ and $296 \mathrm{~nm}$ for FeN), as seen in Table 2.

The Fe oxide phase was analyzed by characterization of Selected Area Electron Diffraction (SAED) patterns. According to the TEM/EDX analysis, there is more $\mathrm{Fe}$ and less $\mathrm{O}$ in the samples than there is from a theoretical calculation for $\mathrm{Fe}_{2} \mathrm{O}_{3}, \mathrm{Fe}_{3} \mathrm{O}_{4}$ or $\mathrm{FeO}$. EDX shows the presence of $\mathrm{Fe}_{3} \mathrm{O}_{2}$ or close to $\mathrm{FeO}$, but since the latter is very rare, $\mathrm{FeO}$ probably did not form. Most likely, there are Fe oxides present with various combinations of oxidation states. Due to the fast kinetics of the USP process, different phases may occur using a single precursor salt, as is seen in previous investigations with USP. When producing $\mathrm{TiO}_{2}$ powder, anatase, rutile and brookite phases were found in the same sample [22].

Table 2. Fe oxide particle sizes in nm from Fe precursor solutions, mean value, standard deviation, minimum, maximum and the number of measured particles from SEM images (n).

\begin{tabular}{|c|c|c|c|}
\hline \multicolumn{4}{|c|}{ Fe Oxide Particle Sizes from Fe Precursor Solutions (nm) } \\
\hline Experiment & FeAc & $\mathrm{FeCl}$ & $\mathrm{FeN}$ \\
\hline MEAN & 261 & 283 & 296 \\
\hline SD & 139 & 145 & 144 \\
\hline MAX & 1537 & 1245 & 918 \\
\hline MIN & 55 & 59 & 42 \\
\hline $\mathrm{n}$ & 1492 & 742 & 532 \\
\hline
\end{tabular}




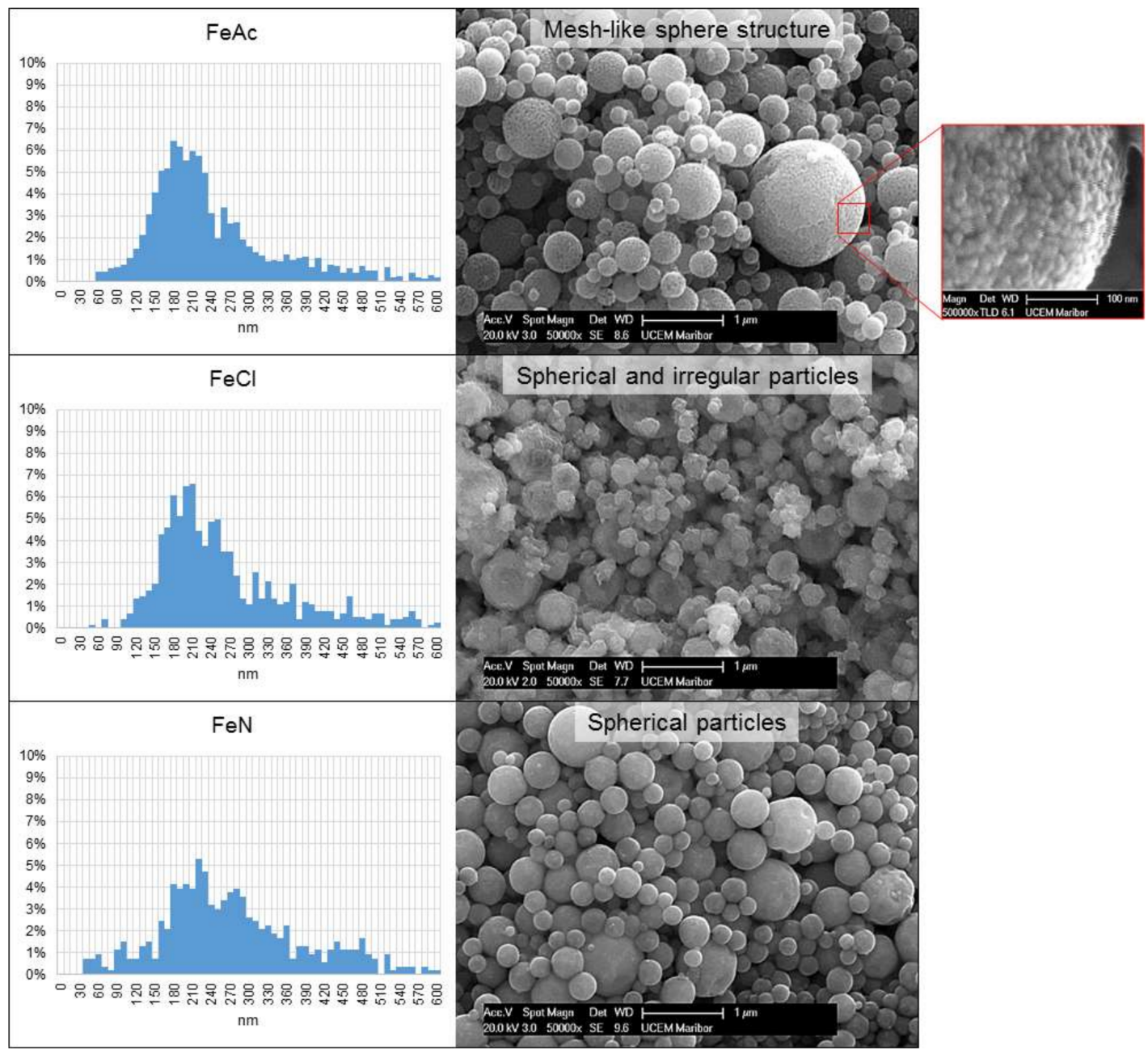

Figure 1. Measured Fe oxide particle size distribution from SEM images, with a corresponding representative SEM image for different precursor salts used with USP. The images show a distinct difference in particle morphology, dependent on the precursor used.

From FeAc, mesh-like structures were formed, in the shape of spheres. Spherical and irregular $\mathrm{Fe}$ oxide particles were formed from $\mathrm{FeCl}$, and mainly spherical shapes were formed from FeN. It can be concluded that the type of precursor (salt used) has a large effect on the particle morphology. Similar results were obtained in a study using Fe (III) acetylacetonate, Fe (II) ammonium citrate, $\mathrm{Fe}$ (III) nitrate and Fe (III) chloride [15]. The organic salt Fe (III) acetylacetonate formed a mesh of small Fe oxide particles, while nitrate formed spheres, and chloride formed irregular particles. Use of different precursors with aerosol processes is well described in the literature [20,21], while the main points for selecting the precursor are solubility and decomposition temperature. The final particle morphologies are dependent on the density, viscosity, surface tension and volatility, or vapor pressure of the precursor solution $[20,21]$. This means a very wide range of precursor salts and solvents can be used with USP, producing an equally large number of different particle compositions, sizes and morphologies. However, similar growth patterns can be seen when using the same salts with different metallic elements (spheres from nitrate [23], a mesh of smaller nanoparticles from acetate [24], irregular particles from chloride [25], similar structures done with Fe [15]). A simple model of particle structure formation is proposed in Figure 2.

Firstly, aerosol droplets of the three precursor solutions are generated and transported into the USP heating zone. The droplet temperature increases, and evaporation with shrinkage occurs. Given that acetate is an organic compound in water, the properties of this solution form nanoparticles 
a few 10 of $\mathrm{nm}$ in size inside the droplet. These primary particles then form larger spheres with agglomeration as the droplet shrinks. Chloride and nitrate as inorganics are still dissolved inside the droplet in the intermediate stage and form solid particles in the USP. The aforementioned rheological properties of the given salts dictate the growth of the particles (isotropic or anisotropic). The nitrate also has the lowest thermal decomposition at $175.68^{\circ} \mathrm{C}$, leaving more energy for densification at higher temperatures. The fast kinetics of USP and the higher energy required for densification of the chloride particles form irregular particles when using this particular Fe salt with USP.

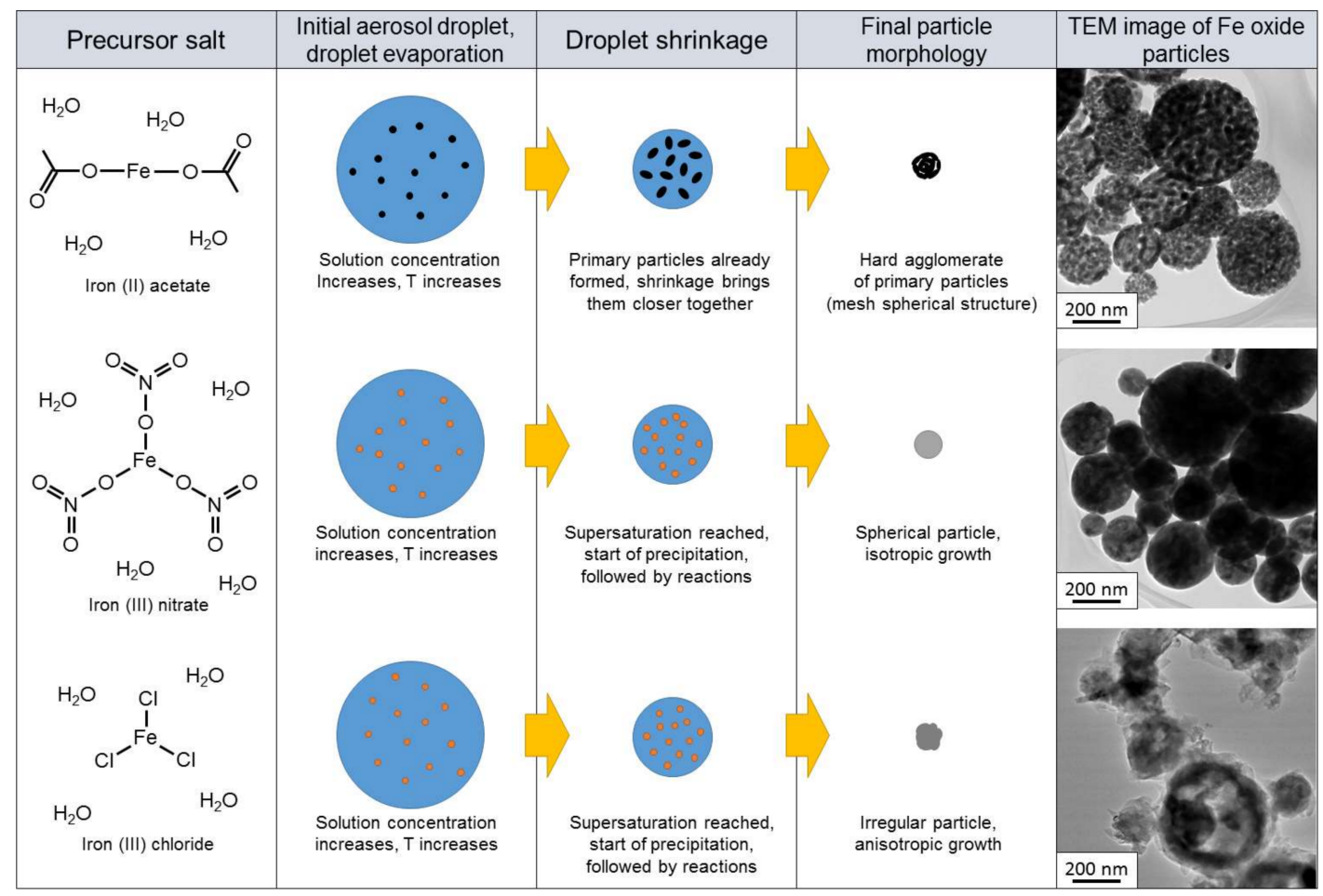

Figure 2. Simple model of Fe oxide particle structure formation inside the USP system, based on the type of precursor salt used.

In the second part of the experiments, trials were made for hybrid Fe/Au particles. For the precursor solution, combinations of Fe chloride with $\mathrm{Au}$ acetate (AuAc), $\mathrm{Au}$ chloride (AuCl) and $\mathrm{Au}$ nitrate $(\mathrm{AuN})$ were chosen (Table 1$)$. These combinations of precursor salts resulted in a precursor solution usable with ultrasonic aerosol generation. Other combinations of precursor salts reacted in water or would need additional additives or treatments for complete solubility and usability with the ultrasonic aerosol generator. There is also one point to consider when preparing a solution with a combination of precursors: similar salt solubilities. A large difference of solubility of two different salt results in a non-uniform composition of particles, because precipitation occurs at different saturation concentrations [21]. As simple mixing of the $\mathrm{FeCl}$ with $\mathrm{Au}$ acetate, nitrate and chloride resulted in clear, yellow-brown solutions, these combinations of precursor salts were considered to be the most favorable for $\mathrm{Fe} / \mathrm{Au}$ particle synthesis. Additionally, $\mathrm{FeCl}$ was mixed with $\mathrm{AuCl}$ in two different concentrations, one having twice the amount of $\mathrm{Au}$ as the other, in order to see the effect of $\mathrm{Au}$ concentration in relation to Fe concentration in the precursor solution.

The resulting Fe/Au particles' sizes and morphologies are seen in Figure 3. A more detailed view of the Au nanoparticle morphologies is seen in Figure 5. Table 3 contains the size values of the corresponding produced particles. Figure 4 shows a representative EDX analysis of the hybrid bimetallic Fe/Au particles, where the Fe oxide particles and AuNPs are identified. 


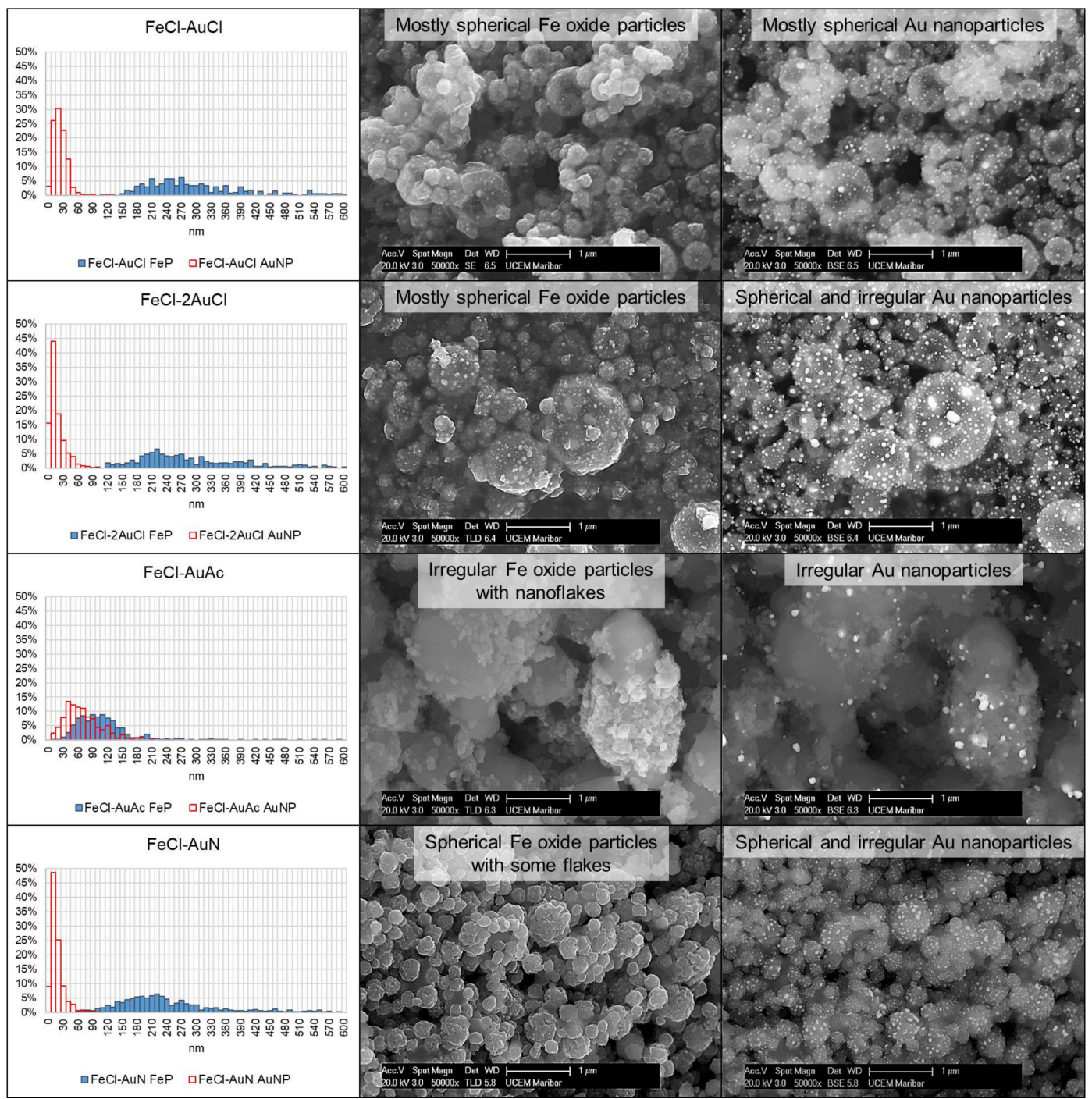

Figure 3. Size distributions of produced Fe/Au particles with corresponding SEM images. The middle column of the figure contains secondary electron images of the produced particles, while the right column has backscattering electron images (Z-number contrast), with a clearly visible contrast difference between the Fe oxide particles with embedded AuNPs (white spots).

Table 3. Fe oxide particle (FeP) and Au nanoparticle (AuNP) sizes in nm from Fe/Au precursor solutions, mean value, standard deviation, minimum, maximum and number of measured particles from SEM images (n).

\begin{tabular}{ccccc}
\hline \multicolumn{5}{c}{ Fe Oxide Particle Sizes from Fe/Au Precursor Solutions (nm) } \\
\hline Experiment & FeCl-AuCl FeP & FeCl-2AuCl FeP & FeCl-AuAc FeP & FeCl-AuN FeP \\
MEAN & 323 & 314 & 160 & 258 \\
SD & 144 & 160 & 195 & 124 \\
MAX & 1327 & 1499 & 1814 & 863 \\
MIN & 115 & 108 & 14 & 70 \\
n & 372 & 338 & 669 & 622 \\
\hline
\end{tabular}


Table 3. Cont.

\begin{tabular}{ccccc}
\hline \multicolumn{5}{c}{ Au nanoparticle sizes from Fe/Au precursor solutions (nm) } \\
Experiment & FeCl-AuCl AuNP & FeCl-2AuCl AuNP & FeCl-AuAc AuNP & FeCl-AuN AuNP \\
MEAN & 28 & 24 & 75 & 22 \\
SD & 14 & 18 & 37 & 13 \\
MAX & 132 & 212 & 211 & 104 \\
MIN & 6 & 2 & 13 & 5 \\
$\mathrm{n}$ & 833 & 1090 & 332 & 898 \\
\hline
\end{tabular}

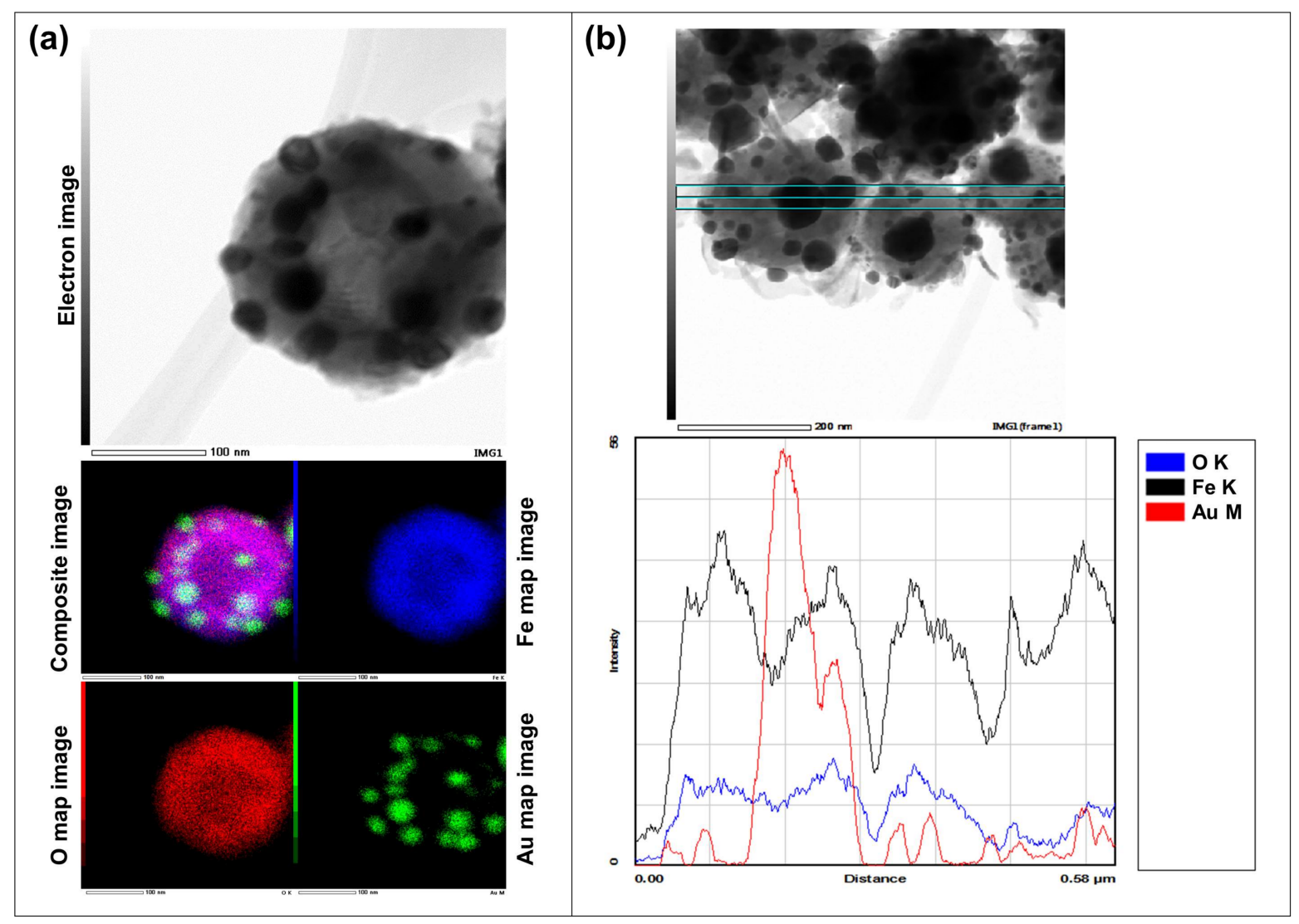

Figure 4. EDX analysis confirmed that AuNPs are on Fe oxide sub-micron sized particles: (a) EDX mapping analysis of a $\mathrm{Fe} / \mathrm{Au}$ particle from the experiment on $\mathrm{FeCl}-\mathrm{AuCl}$; (b) EDX line analysis of $\mathrm{Fe} / \mathrm{Au}$ particles from the experiment on $\mathrm{FeCl}-2 \mathrm{AuCl}$.

\section{1. $\mathrm{FeCl}-\mathrm{AuCl}$}

The $\mathrm{FeCl}-\mathrm{AuCl}$ precursor produced mostly spherical and some irregular Fe oxide particles with a mean size of $323 \mathrm{~nm}$. Gold spherical nanoparticles with some irregularly-shaped nanoparticles with a mean size of $28 \mathrm{~nm}$ were on the Fe oxide nano- and submicron-particles. The mechanisms for precipitation of AuNPs across the volume of larger oxide particles are explained in a previous publication [22]. In those experiments, it was shown that Au precipitated inside the volume and on the surface of $\mathrm{TiO}_{2}$ submicron particles. In our investigation, it is not proven yet if the same synthesis mechanisms have taken place with Fe/AuNPs. The AuNPs are spread randomly around the Fe oxide particles, as seen in SEM and TEM images (Figures 3 and 4).

\section{2. $\mathrm{FeCl}-2 \mathrm{AuCl}$}

The second chloride-chloride precursor had a double Au concentration in the precursor solution (Table 1). The Fe oxide particles are relatively the same as in the experiment on $\mathrm{FeCl}-\mathrm{AuCl}$. Their shapes 
are very similar, mostly spherical shapes with some irregular particles, while their sizes are almost the same, with a mean size of $314 \mathrm{~nm}$, as compared to the mean size of $323 \mathrm{~nm}$ for $\mathrm{FeCl}-\mathrm{AuCl}$. The size distributions are also very similar (Figure 3). We can conclude that the increased Au concentration had no effect on the Fe oxide particles' morphology. However, when we compare the AuNPs in the two Fe/Au hybrid particles, we can clearly see a difference. The backscattering image of experiment $\mathrm{FeCl}-2 \mathrm{AuCl}$ in Figure 3 shows a much larger number of finely-spread smaller nanoparticles, as compared to the image above, corresponding to experiment $\mathrm{FeCl}-\mathrm{AuCl}$. With an AuNP mean size of $24 \mathrm{~nm}$, the AuNPs appear to be finer as compared to $\mathrm{FeCl}-\mathrm{AuCl}$. This is more evident in the size distributions measured from SEM and TEM images. For FeCl-2AuCl, the AuNP distribution is much narrower, indicating that finer and more uniform AuNPs have been synthesized here. We can conclude that increasing the Au concentration produced very fine and more numerous nanoparticles, with a much better consistent spread across the Fe oxide particles.

When comparing the secondary electron and backscatter electron images, several AuNPs can be identified on the surface of Fe oxide particles, which was not as visible with the experiment on $\mathrm{FeCl}-\mathrm{AuCl}$. This may indicate a tendency for the precipitation of AuNPs on the surface of Fe oxide particles. It seems that the formation of Fe oxide precedes AuNP formation in the aerosol. With a high enough Au concentration in the precursor solution, there is a possibility of synthesizing an $\mathrm{Au}$ coating on top of the Fe oxide particles. As these initial trial runs are intended for the feasibility of producing $\mathrm{Fe} / \mathrm{Au}$ particles with the USP method, this should be investigated further with Focused Ion Beam (FIB) milling of the produced particles and TEM tomography for an investigation of the AuNP distribution across the Fe oxide particle volume and with additional $\mathrm{FeCl}-\mathrm{AuCl}$ experiments with different precursor solution concentrations.

\section{3. $\mathrm{FeCl}-\mathrm{AuAc}$}

For the precursor solution preparation, Fe chloride was mixed with Au acetate, previously investigated for pure AuNP synthesis with USP [17], with the chosen concentrations (Table 1). The produced Fe oxide particles mean size is about $160 \mathrm{~nm}$. Examination of the Fe oxide particles shows large irregular particles with very small Fe oxide flakes (Figure 5). This is also seen in the broad size distribution in Figure 3. When compared to only Fe oxide particle shapes from different precursors, we can interpret that the acetate component in the combined precursor solution formed the small flakes, while the chloride component formed irregular particles of greater size.

The secondary electron and backscattered electron image in Figure 3 shows that irregular AuNPs separate from the Fe oxide particles. The AuNPs cover the Fe oxide particles randomly. It seems the AuNPs have precipitated and formed independently from the Fe oxide particles and are now a part of the Fe oxide flake agglomerate. They have a mean measured size of $75 \mathrm{~nm}$, which can be related to the experiments and sizes of pure AuNPs, produced with USP with a precursor solution of similar concentrations [10]. This is also an indicator of possible separate formation of AuNPs from Fe oxide, while further investigation is needed to prove this. The size distribution of AuNPs is also much broader than in all the other experiments (Figure 3), showing a very low uniformity.

The random non-uniform particle shapes and sizes of Fe oxide and the separate AuNP precipitation make the Fe chloride-Au acetate route with USP unsuitable for further studies.

\section{4. $\mathrm{FeCl}-\mathrm{AuN}$}

For the FeCl-AuN experiment precursor solution preparation, Fe chloride was mixed with $\mathrm{Au}$ nitrate and dissolved in deionized water through reflux boiling. Upon examination of the Fe oxide particles, we can observe spherical particles with some agglomerated flakes in spherically-shaped structures. The mean sizes of Fe oxide particles are smaller than previously obtained, about $258 \mathrm{~nm}$. The size distribution for this experiment is also shifted to the left side (smaller particles) as compared to the $\mathrm{FeCl}-\mathrm{AuCl}$ experiments. It seems the nitrate component in the precursor solution has affected the 
Fe oxide particle formation in producing more spherically-shaped particles, without many irregular shapes present.

The AuNPs were measured to have a mean size of about $22 \mathrm{~nm}$, which is similar to the chloride-chloride experiments. The size distribution of AuNPs is narrow, and similar to the experiment on $\mathrm{FeCl}-2 \mathrm{AuCl}$, indicating closely uniform sizes. Upon examining the SEM images, the distribution of AuNPs across $\mathrm{Fe}$ oxide particles is also similar to the experiment on $\mathrm{FeCl}-\mathrm{AuCl}$, and increasing the $\mathrm{Au}$ concentration in the solution should yield similar results to $\mathrm{FeCl}-2 \mathrm{AuCl}$.

As the nitrate component in the precursor solution made more spherical Fe oxide particles and reduced their sizes, apart from the flake agglomerates, the Fe chloride-Au nitrate route has potential for further investigation. As with the experiment on $\mathrm{FeCl}-2 \mathrm{AuCl}$, increasing the $\mathrm{Au}$ concentration in the precursor solution could produce interesting results, with less irregular Fe oxide and more spherical particles; this route may be feasible in producing a Au coating on top of Fe oxide particles. For this purpose, the formation mechanisms should be investigated further through USP parameter investigation or precursor solution additives, in order to avoid the formation of Fe oxide flake agglomerates.

\subsection{DLS and Zeta Potential Measurements}

The zeta potential was measured for all of the samples, for evaluating the stability of the particles in de-ionized (DI) water. The results are shown in Table 4.

Table 4. Zeta potential of the USP-produced particles, suspended in de-ionized water.

\begin{tabular}{ccc}
\hline Sample & Initial Zeta Potential $(\mathbf{m V})$ & Zeta Potential after $\mathbf{6}$ Months $(\mathbf{m V})$ \\
\hline $\mathrm{FeAc}$ & 19.7 & 1.4 \\
$\mathrm{FeCl}$ & 32.8 & 19.0 \\
$\mathrm{FeN}$ & 16.1 & 3.9 \\
$\mathrm{FeCl}-\mathrm{AuCl}$ & 23.7 & 15.6 \\
$\mathrm{FeCl}-\mathrm{AuCl}$ & 26.2 & 11.1 \\
$\mathrm{FeCl}-\mathrm{AuAc}$ & 23.1 & 17.8 \\
$\mathrm{FeCl}-\mathrm{AuN}$ & 22.0 & 14.2 \\
\hline
\end{tabular}

The zeta potential measurements show a moderately low stability of the produced particles in de-ionized water. The stability has also decreased after several months, and the samples have visually agglomerated. This is seen also in the considerable increase in the DLS measured particle sizes of the samples, ranging from around 2-7 $\mu \mathrm{m}$. Increasing the stability would be desirable for further use and research of producing these types of particles with USP. A stabilizing agent should be considered for further investigations.

\subsection{Summary of the Experiments}

Fe chloride-Au chloride and Fe chloride-Au nitrate routes for bimetallic $\mathrm{Fe} / \mathrm{Au}$ particle synthesis with USP are feasible for producing these types of particles with further investigation. The Fe chloride-Au acetate route produces inconsistent results regarding size, shapes and AuNP integration with Fe oxide particles. As such, this initial trial run is not suitable for further investigation, without altering many of the synthesis parameters (technological USP parameters, precursor solution preparation, solution additives, etc.). It is evident that the different combinations of precursors affect the formation in a predictive way. Chloride has a tendency for anisotropic growth and for irregular particles, nitrate for isotropic growth and spherical particles. Acetate produces mesh-like structures. Depending on the ratios of these components in the precursor solution, the formation mechanisms are altered in favor of the dominating component in the mixture. Intermediate products are also formed, depending on the solution mixture. Flakes were formed in the chloride-acetate combination. Some flakes were formed in a structure of spherical agglomerates in the chloride-nitrate combination. 
Figure 5 shows the different particle formations with a more detailed view. As USP is very versatile in producing various metallic oxides, these findings are transferable to acetates, chlorides and nitrates of other metals, as is evident in the research of our group, where similar nanoparticle growth formations were observed, when using different salts for producing pure AuNPs [10,17], or metallic particles of other elements [26].
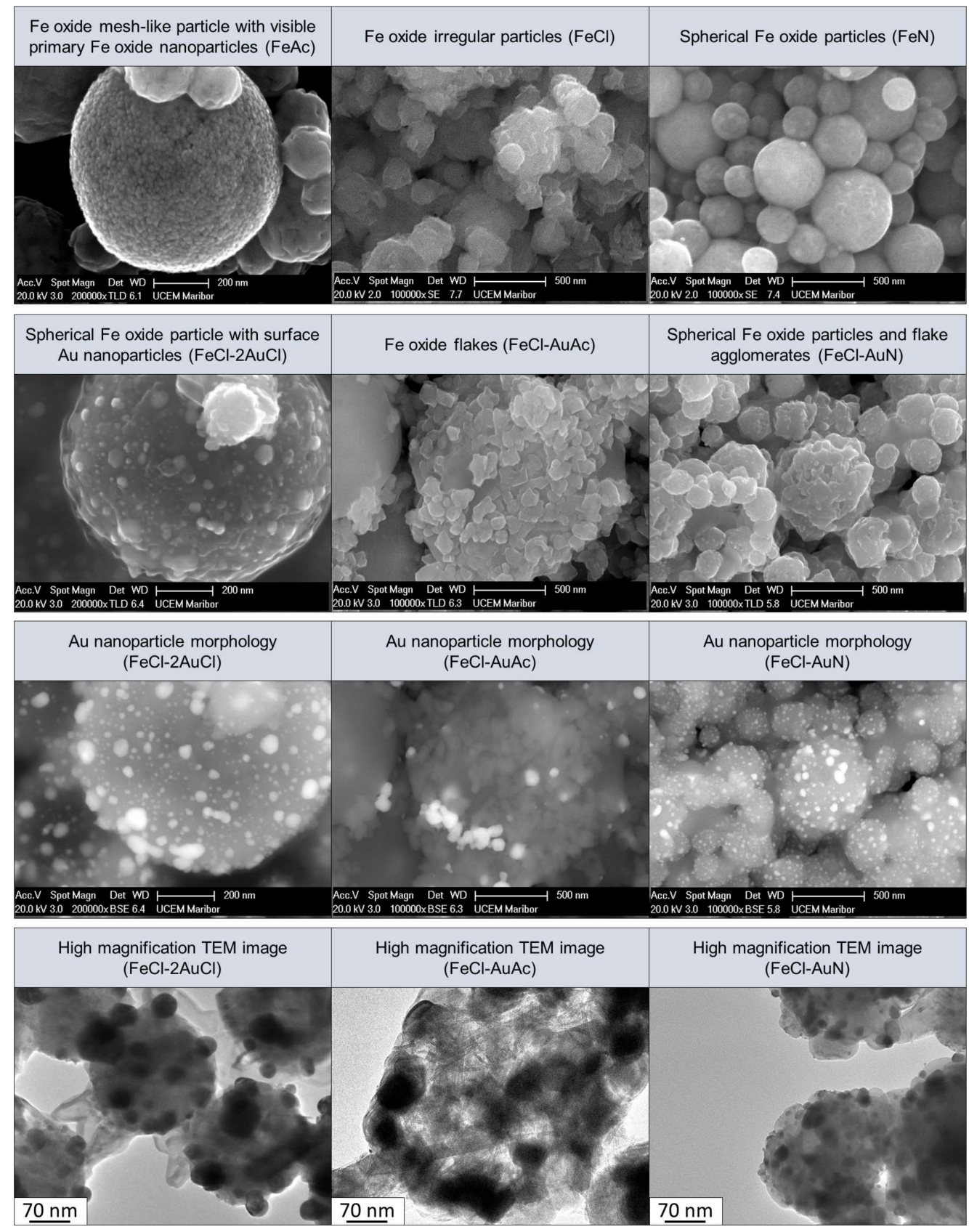

Figure 5. Detailed view of Fe oxide particle morphologies obtained in the experiments.

\section{Conclusions}

Initial investigations were performed into the feasibility of producing $\mathrm{Fe} / \mathrm{Au}$ particles with USP. Firstly, Fe oxide submicron-sized particles were produced using three different Fe salts for preparing the precursor solution for use with USP. Three distinct particle shapes were formed from the precursors, from which the effect was identified of precursor salts on particle formation. The next step 
was producing $\mathrm{Fe} / \mathrm{Au}$ submicron particles with three combinations of Fe chloride with $\mathrm{Au}$ acetate, $\mathrm{Au}$ chloride and Au nitrate. From the experiments performed and the characterizations carried out, we can conclude the following:

- The final form of the synthesized particles with USP depends greatly on the precursor used. Fe acetate forms meshes of Fe oxide nanoparticles; Fe nitrate forms spherical Fe oxide particles; and Fe chloride forms irregular Fe oxide particles. The salt type does not affect the sizes of Fe oxide particles.

- With a one-step USP synthesis of Fe/Au particles, the AuNPs form on Fe oxide particles. The AuNPs become finer and are dispersed more evenly with higher concentrations.

- Using different combinations of precursor salts produces particle shapes that correspond to the given salt. Knowing a salt's effect on final particle morphology, predictions can be made. Intermediate products are also formed. Acetate will produce more mesh-like structures; nitrate will produce more spherical shapes. Chloride promotes anisotropic, irregular shapes.

- For more uniform Fe/Au particle production with USP, combinations of Fe chloride with Au chloride and Fe chloride with Au nitrate can be investigated further. The Fe chloride with $\mathrm{Au}$ acetate combination is not favorable for this endeavor.

The examinations on precursor types and their effect on final particle morphology with USP synthesis may be utilized in other material productions with this method. USP offers a continuous production of particles, with relative ease of scalability. This is an advantage compared to other methods of fine powder production. As such, it can be implemented more easily at an industrial scale.

Acknowledgments: This research was co-financed by the Ministry of Education, Science and Sport, Republic of Slovenia (Program MARTINA-MAteRials and Technologies for New Applications, OP20.00369). The authors acknowledge the financial support from the Slovenian Research Agency (Research Core Funding No. P2-0120 and P2-0132, BI-DE/17-19-12). The authors greatly acknowledge Gerhard Dehm and Christian Liebscher from Structure and Nano-/Micromechanics of Materials at the Max-Planck-Institut für Eisenforschung GmbH in Düsseldorf, Germany for using transmission electron microscopes and related techniques.

Author Contributions: Rebeka Rudolf, Bernd Friedrich and Peter Majerič designed the research, performed the experiments and analyzed the data. Darja Jenko provided the analysis tools and performed the characterization. Peter Majerič wrote the article.

Conflicts of Interest: The authors declare no conflict of interest.

\section{References}

1. Ban, Z.; Barnakov, Y.A.; Li, F.; Golub, V.O.; O'Connor, C.J. The synthesis of core-shell iron@gold nanoparticles and their characterization. J. Mater. Chem. 2005, 15, 4660-4662. [CrossRef]

2. Calvo, F.; Combe, N.; Morillo, J.; Benoit, M. Modeling Iron-Gold Nanoparticles Using a Dedicated Semi-Empirical Potential: Application to the Stability of Core-Shell Structures. J. Phys. Chem. C 2017, 121, 4680-4691. [CrossRef]

3. Hoskins, C.; Min, Y.; Gueorguieva, M.; McDougall, C.; Volovick, A.; Prentice, P.; Wang, Z.; Melzer, A.; Cuschieri, A.; Wang, L. Hybrid gold-iron oxide nanoparticles as a multifunctional platform for biomedical application. J. Nanobiotechnol. 2012, 10, 27. [CrossRef] [PubMed]

4. Kayal, S.; Ramanujan, R.V. Anti-Cancer Drug Loaded Iron-Gold Core-Shell Nanoparticles (Fe@Au) for Magnetic Drug Targeting. J. Nanosci. Nanotechnol. 2010, 10, 5527-5539. [CrossRef] [PubMed]

5. Stafford, S.; Serrano Garcia, R.; Gun'ko, Y.K. Multimodal Magnetic-Plasmonic Nanoparticles for Biomedical Applications. Appl. Sci. 2018, 8, 97. [CrossRef]

6. Kwizera, E.A.; Chaffin, E.; Wang, Y.; Huang, X. Synthesis and properties of magnetic-optical core-shell nanoparticles. RSC Adv. 2017, 7, 17137-17153. [CrossRef] [PubMed]

7. Sohn, Y.; Pradhan, D.; Kang, J.-S.; Leung, K.T. Nanoscale architecture of bimetallic hybrid Fe-Au nanostructures with and without 1,4-phenylene diisocyanide pre-functionalization. RSC Adv. 2015, 5, 31472-31478. [CrossRef] 
8. Swiatkowska-Warkocka, Z.; Koga, K.; Kawaguchi, K.; Wang, H.; Pyatenko, A.; Koshizaki, N. Pulsed laser irradiation of colloidal nanoparticles: A new synthesis route for the production of non-equilibrium bimetallic alloy submicrometer spheres. RSC Adv. 2012, 3, 79-83. [CrossRef]

9. Swiatkowska-Warkocka, Z.; Pyatenko, A.; Koga, K.; Kawaguchi, K.; Wang, H.; Koshizaki, N. Various Morphologies/Phases of Gold-Based Nanocomposite Particles Produced by Pulsed Laser Irradiation in Liquid Media: Insight in Physical Processes Involved in Particles Formation. J. Phys. Chem. C 2017, 121, 8177-8187. [CrossRef]

10. Majerič, P.; Jenko, D.; Friedrich, B.; Rudolf, R. Formation mechanisms for gold nanoparticles in a redesigned Ultrasonic Spray Pyrolysis. Adv. Powder Technol. 2017, 28, 876-883. [CrossRef]

11. Bang, J.H.; Suslick, K.S. Applications of Ultrasound to the Synthesis of Nanostructured Materials. Adv. Mater. 2010, 22, 1039-1059. [CrossRef] [PubMed]

12. Tsai, S.C.; Song, Y.L.; Tsai, C.S.; Yang, C.C.; Chiu, W.Y.; Lin, H.M. Ultrasonic spray pyrolysis for nanoparticles synthesis. J. Mater. Sci. 2004, 39, 3647-3657. [CrossRef]

13. Santoyo Salazar, J.; Perez, L.; de Abril, O.; Truong Phuoc, L.; Ihiawakrim, D.; Vazquez, M.; Greneche, J.-M.; Begin-Colin, S.; Pourroy, G. Magnetic Iron Oxide Nanoparticles in 10-40 nm Range: Composition in Terms of Magnetite/Maghemite Ratio and Effect on the Magnetic Properties. Chem. Mater. 2011, 23, 1379-1386. [CrossRef]

14. Laurent, S.; Forge, D.; Port, M.; Roch, A.; Robic, C.; Vander Elst, L.; Muller, R.N. Magnetic Iron Oxide Nanoparticles: Synthesis, Stabilization, Vectorization, Physicochemical Characterizations, and Biological Applications. Chem. Rev. 2008, 108, 2064-2110. [CrossRef] [PubMed]

15. González-Carreño, T.; Morales, M.P.; Gracia, M.; Serna, C.J. Preparation of uniform $\gamma-\mathrm{Fe}_{2} \mathrm{O}_{3}$ particles with nanometer size by spray pyrolysis. Mater. Lett. 1993, 18, 151-155. [CrossRef]

16. Wu, Y.-N.; Wu, P.-C.; Yang, L.-X.; Ratinac, K.R.; Thordarson, P.; Jahn, K.A.; Chen, D.-H.; Shieh, D.-B.; Braet, F. The anticancer properties of iron core-gold shell nanoparticles in colorectal cancer cells. Int. J. Nanomed. 2013, 8, 3321-3331. [CrossRef] [PubMed]

17. Shariq, M.; Majerič, P.; Friedrich, B.; Budic, B.; Jenko, D.; Dixit, A.R.; Rudolf, R. Application of Gold(III) Acetate as a New Precursor for the Synthesis of Gold Nanoparticles in PEG Through Ultrasonic Spray Pyrolysis. J. Clust. Sci. 2017, 28, 1647-1665. [CrossRef]

18. Bogović, J.; Stopić, S.; Friedrich, B. Nanosized metallic oxide produced by Ultrasonic Spray Pyrolysis. In Proceedings of the European Metallurgical Conference, Düsseldorf, Germany, 26-29 June 2011.

19. Schneider, C.A.; Rasband, W.S.; Eliceiri, K.W. NIH Image to ImageJ: 25 years of image analysis. Nat. Methods 2012, 9, 671-675. [CrossRef] [PubMed]

20. Kodas, T.T.; Hampden-Smith, M.J. Aerosol Processing of Materials, 1st ed.; Wiley-VCH: New York, NY, USA, 1998; ISBN 978-0-471-24669-5.

21. Jung, D.S.; Park, S.B.; Kang, Y.C. Design of particles by spray pyrolysis and recent progress in its application. Korean J. Chem. Eng. 2010, 27, 1621-1645. [CrossRef]

22. Alkan, G.; Rudolf, R.; Bogovic, J.; Jenko, D.; Friedrich, B. Structure and Formation Model of $\mathrm{Ag} / \mathrm{TiO}_{2}$ and $\mathrm{Au} / \mathrm{TiO}_{2}$ Nanoparticles Synthesized through Ultrasonic Spray Pyrolysis. Metals 2017, 7, 389. [CrossRef]

23. Pingali, K.C.; Rockstraw, D.A.; Deng, S. Silver Nanoparticles from Ultrasonic Spray Pyrolysis of Aqueous Silver Nitrate. Aerosol Sci. Technol. 2005, 39, 1010-1014. [CrossRef]

24. Lee, S.D.; Nam, S.-H.; Kim, M.-H.; Kim, Y.D.; Boo, J.-H. Synthesis of ZnO nanoparticles by spray-pyrolysis method and their photocatalytic effect. In Proceedings of the 2010 3rd International Nanoelectronics Conference (INEC), HongKong, China, 3-8 January 2010; pp. 572-573.

25. Yu, J.-K.; Suh, S.-K.; Choi, J.-H.; Sohn, J.-G. Manufacture of Ultra Fine CuO Powder from Waste Copper Chloride Solution by Spray Pyrolysis Process. Geosyst. Eng. 2002, 5, 13-19. [CrossRef]

26. Bogovic, J.; Rudolf, R.; Friedrich, B. The Controlled Single-Step Synthesis of $\mathrm{Ag} / \mathrm{TiO} 2$ and $\mathrm{Au} / \mathrm{TiO} 2$ by Ultrasonic Spray Pyrolysis (USP). JOM J. Miner. Met. Amp Mater. Soc. 2015, 68, 330-335. [CrossRef]

(C) 2018 by the authors. Licensee MDPI, Basel, Switzerland. This article is an open access article distributed under the terms and conditions of the Creative Commons Attribution (CC BY) license (http:/ / creativecommons.org/licenses/by/4.0/). 